\title{
La Distribución de Competencias entre el Poder Central y las Autonomías Territoriales en los Modelos Federales Europeos*
}

\author{
Emilia Girón Reguera** \\ Profesora Derecho Constitucional- \\ Universidad de Cádiz (España)
}

\begin{abstract}
The article describes the systems of distribution of competences between the Federation and the Member States in Germany, Austria, Belgium and Switzerland. It emphasizes that two institutions ensure the smooth running of the division of competences: the parliamentary Camera of territorial representation and the Constitutional Federal Court. The approach to these questions of the federal States could contribute to the current debate on the restructuring of the territorial Colombian pattern, since any State, as Colombia, that seeks to deepen and advance in the path of the political decentralization must face up to the following tasks: the regulation of a clear delimitation of competitions, supplemented with appropriate cooperation mechanisms; the configuration of a territorial parliamentary Camera -which provides an effective way where the territorial intermediate entities can defend their interests when the laws of the Republic are elaborated and approved - and the existence of a judicial organ which resolves the territorial conflicts.
\end{abstract}

Key Words.

Federal Status, distribution of competences, Cooperative Federalism, territorial parliamentary Camera, Constitutional Federal Court.

\section{Resumen}

El artículo describe los sistemas de reparto competencial entre la Federación y los Estados Miembros en Alemania, Austria, Bélgica y Suiza. Subraya el importante papel que para su óptimo funcionamiento juegan dos instituciones: la Cámara Parlamentaria de Representación Territorial y el Tribunal Constitucional Federal. La aproximación a estas cuestiones de los Estados federales reviste interés en un momento en el que se discute la reestructuración del modelo territorial colombiano, por cuanto son tareas ineludibles en todo Estado que, como Colombia, pretenda ahondar y avanzar en el sendero de la

Fecha de recepción del artículo: 20 de abril de 2007

Fecha de aceptación del artículo: 13 de mayo de 2007

* Resultado proyecto de investigación: ¿Hacia dónde debe orientarse la organización territorial en Colombia? (AI 14/04), ejecutado conjuntamente por el Centro de Investigaciones Socio-Jurídicas de la Facultad de Derecho de la Universidad Libre - Sede Bogotá (Colombia) y el Área de Derecho Constitucional de la Universidad de Cádiz (España), previa subvención de la Junta de Andalucía (2004 - 2007).

** Profesora Asociada de Derecho Constitucional de la Universidad de Cádiz, Coinvestigador del Grupo de Investigación Estado, Derecho y Territorio (Categoría A - Colciencias), dirigido por la Dra. Liliana Estupiñán Achury - Categoría A Colciencias, así como del Grupo español de investigación La comparación en Derecho Constitucional: tendencias contemporáneas, dirigido por el Dr. Miguel Revenga. 
descentralización política: la regulación de una nítida delimitación de competencias, complementada con adecuados mecanismos de cooperación; la configuración de una Cámara parlamentaria de carácter territorial que sea un cauce eficaz donde las entidades territoriales intermedias puedan hacer valer sus intereses en la elaboración y aprobación de las leyes de la República- y la existencia de un órgano jurisdiccional independiente para la resolución de los conflictos territoriales.

\section{Palabras clave.}

Estado federal, Reparto competencial, Federalismo cooperativo, Cámara de representación territorial, Tribunal Constitucional Federal.

\section{Problema de investigación y método}

Uno de los grandes retos que tiene el diseño de un nuevo modelo territorial en Colombia es la reordenación de las competencias entre sus entidades territoriales, de la que dependerá, en gran medida, el grado de descentralización. La federalización del país figura entre las propuestas que se han barajado para acometer el tan necesario proceso de reestructuración territorial. Por tal razón, este trabajo aborda, desde el método de derecho comparado, la explicación de la forma en la que se ha operado el reparto territorial de competencias entre la Federación y los Estados Federados en Alemania, Austria, Bélgica y Suiza. La aproximación a las experiencias federales de estos países resulta de suma utilidad, porque permite conocer otras posibles alternativas, de las que pueden extraerse enseñanzas, aún siendo conscientes de que es sumamente arriesgado trasladar concretas instituciones o fórmulas, aun cuando funcionen de modo óptimo en otros sistemas, sin un previo análisis en el que se valore su idoneidad en un contexto socio-político distinto de aquél en el que han surgido.

La ordenación de las competencias según las pautas del federalismo cooperativo

En los países federales objeto de estudio se aprecian algunas tendencias comunes. En primer lugar, la creciente concentración del poder legislativo en la Federación, en particular en las materias económicas y sociales, justificada en la necesidad de garantizar la unidad económica y unas condiciones equivalentes de vida, así como la articulación del reparto competencial conforme a las pautas propias de un federalismo interrelacional o cooperativo, consistente en un alto grado de cooperación negociada entre las Administraciones territoriales en el desarrollo de políticas públicas, la existencia de un importante número de competencias compartidas y de técnicas de financiación mixta. Estas prácticas, con frecuencia extra constitucionales, pero amparadas por la jurisprudencia constitucional, han alterado, en cierta medida, el esquema original de distribución de competencias, por cuanto han facilitado la injerencia de la Federación en ámbitos competenciales reservados constitucionalmente a los Estados miembros, lo que ha conllevado, en última instancia, a un reforzamiento de los poderes federales en detrimento de aquéllos inicialmente otorgados a las entidades federadas.

En segundo lugar, en el federalismo germánico y en el ordenamiento suizo ha prosperado lo que se conoce con el nombre de federalismo de ejecución, consistente en atribuir un poder general a las entidades federadas para aplicar las leyes, incluidas las funciones ejecutivas en materia de legislación federal, salvo previsión expresa en contrario. Por tal razón, dominan las fórmulas de administración indirecta, siendo escasas, y sólo en relación con determinados servicios, las oficinas federales periféricas. No obstante, el derecho belga no conoce la técnica del federalismo administrativo.

Finalmente en estos países, como es la regla general en todos los Estados Compuestos, las 
normas federadas no se ordenan según pautas de jerarquía o subordinación -excepto respecto de la Constitución federal-, sino de acuerdo con reglas más complejas, entre las que se destaca el principio de competencia o separación. No obstante, en caso de conflictos entre ordenamientos irresolubles por el principio de competencia, en Alemania y Suiza se establece la regla de prevalencia del derecho federal, en Austria tal cláusula de primacía se refiere sólo a las leyes federales constitucionales respecto a las leyes de los Länder, mientras que en Bélgica no se menciona una regla de estas características.

En tal análisis de los sistemas de distribución competencial ha sido necesario traer a colación el grado de representación de las entidades federadas en la composición de la segunda cámara parlamentaria existente en todas las federaciones, como Cámara de representación territorial (Senado, Cámara Alta o Consejo Federal), así como las funciones que tiene asignadas en cada sistema, por cuanto puede constituir una importante vía, aunque indirecta, para que los Estados Federados participen en la legislación federal e intervengan en el diseño de la política de la Federación. El papel desempeñado por la Cámara Alta en las funciones legislativas federales varía considerablemente, siendo muy común en el federalismo germánico y suizo, con un relativo protagonismo en el caso belga y con una importancia modesta en el modelo austriaco. Y, por idéntica razón, se ha hecho referencia al Tribunal Constitucional o Alta Corte federal, existente en todos los países con pluralismo territorial, como una instancia competente para resolver los conflictos de competencias entre federación y entidades federadas, lo que contribuye, en gran medida, a una mejor definición de los ámbitos competenciales. Pese a la neutralidad que caracteriza a este órgano en todos los sistemas, existirá una mayor sensibilidad hacia los intereses de los Estados Federados, cuando éstos intervengan de forma decisiva en la composición del Senado y a éste le corresponda, a su vez, el nombramiento de algunos miembros del órgano de justicia constitucional.
El sistema constitucional de reparto competencial en Alemania: un federalismo participativo

La República Federal de Alemania es un país con una larga y consolidada tradición federal, cuyos niveles intermedios de gobierno o Länder (Estados Federados o Estados-miembros) disponen de una considerable autonomía política. Desde la unificación de las dos Alemanias en 1990, la Federación (Bund) está conformada por 16 Länder: Baden-Wurtemberg, Baviera, Berlín, Brandenburgo, Bremen, Hamburgo, Hesse, Mecklemburgo-Pomerania, Baja Sajonia, Renania del Norte-Westfalia, RenaniaPalatinado, Sarre, Sajonia, Sajonia-Anhalt, Schleswig-Holstein y Turingia.

La Ley Fundamental (Grundgesetz) de 1949 (en adelante LF), sustentada en el principio federal, no creó una forma de organización territorial, sino que se limitó a plasmar la ya existente, dado que los Länder eran una realidad anterior a la de la República Federal, por cuanto el federalismo alemán posee unas profundas raíces históricas. El principio federal queda salvaguardado por la cláusula de intangibilidad contenida en el art. 79.3 LF, que declara inadmisible cualquier modificación constitucional que tenga por objeto la articulación del Bund en Länder, la participación de los Länder en la legislación o los principios enunciados en los artículos 1 y 20, que, en su primer apartado, define a la República federal alemana como "Estado Federal".

En virtud de su autonomía constitucional, los Länder poseen capacidad para darse a sí mismos su propia Constitución, si bien, en virtud del art. 28 LF, tal orden constitucional deberá responder a los principios del Estado de Derecho Republicano, Democrático y Social, y el pueblo deberá tener una asamblea representativa elegida por sufragio universal, directo, igual, libre y secreto.

Una detallada delimitación de competencias se encuentra en la propia Constitución alemana, 
que parte de la presunción general de competencias a favor de los Länder, al afirmar en su artículo 30 LF que "el ejercicio de las facultades estatales y el cumplimiento de las funciones estatales corresponden a los Länder en todos los casos en que la presente Ley Fundamental no establezca o permita otra solución normativa". El sistema competencial ha sido objeto de una profunda reordenación con la reforma constitucional del 2006, con la que se ha pretendido un reparto más definido de los poderes y funciones del Bund y de los Länder, reduciendo los casos de imbricación política (Politikverflectungsfalle), de forma que se evidencie más claramente cuál es la competencia y la responsabilidad de cada nivel de gobierno.

Con relación a las competencias legislativas, la Ley Fundamental establece un doble listado de competencias federales diferenciadas en dos categorías: legislación federal exclusiva y legislación federal concurrente. En primer lugar, se enumera de forma expresa las materias que son competencia legislativa exclusiva de la Federación ${ }^{1}$.

Sobre ellas, el Bund posee el derecho único para legislar, pero puede autorizar a los Länder para legislar en estos ámbitos mediante una expresa Ley Federal (arts. 71, 73 y 105.1 LF). Además, la Ley Fundamental contiene en su articulado otras reservas de ley federal para la regulación de determinadas materias, como es el caso de la objeción de conciencia (art. 4.3 LF), de los partidos políticos (art. 21.3 LF) o las elecciones al Bundestag (art. 38.3 LF). Con la reforma de 2006 el Bund ha asumido algunas nuevas competencias, pero en menor medida que los Länder ${ }^{2}$, sobre materias que antes eran de legislación concurrente (permisos de armas, determinadas clases de pensiones y energía nuclear), del ámbito de las competencias marco (empadronamiento y expedición de documentos de identidad y la protección de bienes culturales ante traslados al extranjero) o que no se encontraban recogidas en los listados (terrorismo internacional).
En segundo lugar, se establece un largo listado de materias objeto de la legislación concurrente en los arts. 74 y 74.a LF ${ }^{3}$. Se trata de un sistema peculiar, por cuanto legislación concurrente no

${ }^{1}$ Las materias de competencia legislativa exclusiva de la Federación son las siguientes: los asuntos exteriores, la defensa y la protección civil; la nacionalidad; la libertad de circulación, el régimen de pasaportes, la inmigración, la emigración y la extradición; el sistema de cambios, monetario y de acuñación, pesas y medidas, así como la fijación de la hora oficial; la unidad aduanera y comercial, los tratados de comercio y navegación, la libre circulación de mercancías y el intercambio de productos y financiero con el exterior, incluyendo la protección de aduanas y fronteras; el tráfico aéreo; el tráfico de ferrocarriles que pertenezcan total o mayoritariamente a la Federación, la construcción, el mantenimiento y la explotación de las vías férreas; los correos y las telecomunicaciones; el estatuto del personal al servicio de la Federación; el derecho de propiedad industrial, los derecho de autor y los derechos de edición; y la colaboración entre la Federación y los Länder en materia de política criminal, de defensa de la Constitución y para la protección contra los intentos realizados dentro del territorio federal mediante el uso de la fuerza o efectuando preparativos para tal fin, que pongan en peligro los intereses de la República Federal de Alemania en el exterior, así como en relación con la creación de una organización federal de policía criminal y la lucha internacional contra la criminalidad.

${ }^{2}$ Por tanto, las nuevas competencias exclusivas de la Federación son: la reglamentación de armas y explosivos; las pensiones de los inválidos de guerra y las familias de las víctimas de guerra y la asistencia a los antiguos prisioneros de guerra; la energía nuclear; el sistema de empadronamiento y de documentos de identidad; la protección del patrimonio cultural alemán ante su traslado al extranjero y la regulación de funciones y atribuciones preventivas de la Agencia Federal de Investigación Criminal para combatir el peligro del terrorismo internacional.

${ }^{3}$ Son materias de legislación concurrente: el derecho civil, el derecho penal y el régimen penitenciario, la organización y el procedimiento judicial, el régimen de la abogacía, del notariado y del asesoramiento jurídico; el estado civil; el derecho de asociación; el derecho de estancia y establecimiento de los extranjeros; los asuntos referentes a refugiados y a expulsados; la asistencia social; los daños de guerra y reparaciones; las tumbas de los caídos en combate y de otras víctimas de la guerra y de la tiranía; el Derecho de la economía (minas, industria, economía de la energía, artesanía, comercio, sistema bancario y de mercado de valores, seguros de derecho privado); el derecho laboral; las ayudas para la formación y la promoción de la investigación científica; el derecho de expropiación; el sometimiento del suelo, de las riquezas naturales y los medios de producción a un régimen de propiedad colectiva o de otras formas de gestión colectiva; la prevención del abuso del poder económico; el fomento de la producción agrícola y forestal, la garantía de avituallamientos, la importación y exportación de productos agrícolas y forestales, la pesca de altura y de bajura, la protección de costas; el derecho del suelo; las medidas contra las epidemias para la comunidad; la admisión a profesiones médicas y otras profesiones curativas, así como el comercio de medicamentos y otras substancias; la financiación de hospitales y la regulación de las tarifas hospitalarias; la protección relativa al comercio de productos alimenticios y estimulantes, incluidos los productos procedentes de animales, así como la protección de las plantas y animales; la navegación de alta mar y de cabotaje, así como las señales marítimas, la navegación interior, el servicio meteorológico, vías marítimas navegables y vías interiores navegables al servicio del tráfico público; el tráfico por carreteras, automóviles, construcción y mantenimiento de carreteras para el tráfico a larga distancia; los ferrocarriles que no sean federales, con excepción de los de montaña; la eliminación de basuras, el reciclaje, la purificación el aire y la lucha contra el ruido; la responsabilidad del Estado; la inseminación artificial humana, la investigación sobre manipulaciones genéticas, así como la regulación del trasplante de órganos y tejidos; la regulación de los derechos y obligaciones de los funcionarios, excluido el régimen retributivo que recuperan los Länder, pese a que la Federación lo había acabado asumiendo en aras de la igualdad. A las que se han sumado las siguientes materias que antes eran objeto de competencia marco: la caza; la protección de la naturaleza y el cuidado del paisaje; la distribución de la tierra, la ordenación del territorio y el régimen hidráulico; y el acceso y finalización de la enseñanza universitaria. 
significa actividad legislativa conjunta de la Federación y los Länder, sino que los Länder podrán legislar sobre tales materias sólo en tanto no lo haga la Federación, pero cuando ésta ejercite su facultad legislativa, la legislación federal que sea dictada desplazará automáticamente las normas que pudieran haber sido dictadas por las entidades federadas.

Hasta la reforma de 2006 se consideraba que el Bund estaba legitimado para legislar sobre todas las materias relacionadas en el art. $74 \mathrm{LF}$ siempre y cuando existiera la necesidad de una disciplina legislativa federal. Esta necesidad concurre, en primer lugar, cuando así lo requiera la creación de condiciones de vida equivalentes en el territorio federal, bien porque sobre un determinado asunto no sería eficaz una regulación individual de cada uno de los Länder o bien porque la regulación sobre un determinado asunto por un Land perjudicara los intereses de otro Land; y, en segundo lugar, cuando sea indispensable para la preservación de la unidad jurídica o económica en interés general del Estado (art. 72.2 LF). Se trataba de una cláusula poco precisa e indeterminada, inspirada en el principio de subsidiariedad, y que, al ser interpretada ampliamente por el Tribunal Constitucional Federal, dejó expedito el camino para que la Federación asumiera progresivamente todas las materias de competencia legislativa concurrente, la cual abarca un listado bastante extenso, superior incluso a las materias sobre las que tienen una competencia exclusiva, excluyendo a los Länder de tales ámbitos normativos. De forma que las materias de legislación concurrente acababan siendo convertidas en exclusivas de facto.

Tras la reforma constitucional del 2006 se ha reformulado el catálogo de competencias concurrentes, ya que algunas de ellas han pasado a ser asumidas en exclusividad por el Bund o por los Länder, pero lo más novedoso es que se ha excluido gran parte de las materias pertenecientes a competencias concurrentes de la actual "cláusula de necesidad". En consecuencia, la Federación será libre de decidir si regula o no, eximiéndose de la obligación de acreditar la concurrencia de las condiciones del art. 72.2 LF, esto es, de demostrar la necesidad de una regulación federal unitaria. Se posibilita así que un tercio de las materias concurrentes devengan, de facto, exclusivas del Bund, puesto que se eliminan los límites para que éste pueda ejercer la competencia concurrente, abarcando todo el campo normativo, con el consiguiente desplazamiento de las normas previas de los Länder ${ }^{4}$. La reducción del ámbito de aplicación de la cláusula contenida en el art. 72.2 LF refuerza la posición de la Federación, lo que ha sido compensado, además, con la conversión de algunas de las competencias concurrentes y de las competencias marco en exclusivas de los Länder; con la posibilidad reconocida a los Länder de apartarse de la legislación del Bund en algunas materias ${ }^{5}$. De esta forma, los Länder quedan facultados para recuperar el espacio normativo ocupado por la Federación mediante el ejercicio de la facultad legislativa en determinadas materias de competencia concurrente. En tales supuestos, la normativa del Bund entrará en vigor como mínimo a los seis meses de su promulgación, salvo que se adoptase una decisión distinta por mayoría en el Bundesrat, de forma que los Länder tengan un margen de tiempo para decidir si desean preparar una legislación propia que la sustituya o no. La

\footnotetext{
${ }^{4}$ Conforme el nuevo art. 72.2 LF, las materias de legislación concurrente a las que seguirán siendo aplicables los requisitos en él indicados son: derecho de residencia y establecimiento de los extranjeros; la asistencia social; el Derecho económico (minería, industria, energía, artesanía, comercio, sistema bancario y bursátil, seguros de Derecho Privado); la regulación de las ayudas para la formación y la promoción de la investigación científica; el régimen de transferencia de la tierra, de los recursos naturales y los medios de producción a un régimen de propiedad colectiva o a otras formas de economía colectiva; la financiación de los hospitales y regulación de las tarifas de los mismos; la protección relativa al comercio de productos alimenticios y estimulantes, de productos de primera necesidad, piensos, semillas y plantas agrícolas y forestales, protección de las plantas contra enfermedades y parásitos, así como la protección de animales; el tráfico por carretera, automóviles, construcción y mantenimiento de las carreteras para el tráfico de largo recorrido, así como la percepción y distribución de ingresos por el uso de carreteras públicas con vehículos; la responsabilidad del Estado; la inseminación artificial humana, la investigación sobre manipulaciones genéticas, así como las regulaciones sobre trasplante de órganos y tejidos.

${ }^{5}$ Las materias de legislación concurrente en las que los Länder se pueden apartar de la normativa del Bund son: la caza, excepto la normativa sobre licencias de caza; el medio ambiente, excepto los principios generales de la protección de la naturaleza, el derecho de protección de las especies o de protección de la naturaleza marina; el reparto del suelo; la ordenación territorial; el régimen hidráulico, excepto la regulación relativa a sustancias o a instalaciones; el acceso y finalización de la enseñanza universitaria.
} 
incorporación de este derecho a divergir posibilita la existencia de regímenes normativos desiguales entre los Länder para las concretas materias indicadas, lo que puede hacer tambalear un principio fundamental que ha caracterizado al Estado federal alemán cuál es la uniformidad de las condiciones de vida de los ciudadanos, que legitima el ejercicio de las competencias concurrentes por parte de la Federación y justifica ayudas financieras a los Länder.

La reforma de 2006 ha suprimido una tercera categoría de competencias federales que era la legislación federal básica o marco. A través de las competencias legislativas marco, la Federación, en el supuesto de que concurrieran las mismas condiciones de necesidad previstas para la legislación concurrente, tenía potestad, a través de las llamadas "leyes marco" o "leyes básicas" (Rahmenvorschriften), para establecer las directrices que habrían de seguir los Länder en su concreta legislación sobre una serie de materias que eran enumeradas de forma expresa (la función pública, los principios generales de la enseñanza superior, el régimen jurídico general de los medios de comunicación, la protección del medio ambiente, el régimen jurídico de los jueces, la ordenación del territorio y el régimen hidráulico, etc.). Las disposiciones marco debían dejar a los legisladores de los Länder una esfera de actuación amplia para desarrollar tales disposiciones a través de sus propias regulaciones sustanciales, por lo que sólo excepcionalmente podía la legislación marco entrar en detalles o contener una regulación de aplicación inmediata. Sin embargo, la Federación tendió a realizar un uso abusivo de las mismas, sobrepasando con sus normas lo que correspondía a un mero marco normativo. Por tal razón, la reforma constitucional ha optado por su supresión, al otorgar en exclusiva, bien a la Federación bien a los Länder, la regulación plena de las materias objeto de dicha competencia o configurándolas como competencias concurrentes.

Aquellas materias que la Federación no tenga asignadas dentro del campo de la legislación, serán de la incumbencia de los Länder. La cláusula residual opera así a favor de éstos, los cuales tienen facultad legislativa en todo aquello en lo que la Ley Fundamental no confiera potestades legislativas al Bund (art. 70.1 LF). Por tanto, la delimitación de las materias de legislación exclusiva de los Länder, ante la ausencia de una relación constitucional detallada, ha resultado de excluir las competencias legislativas de la Federación de las materias posibles de regulación, lo que evidencia, no obstante, un núcleo reducido, aunque no poco importante; de competencias legislativas propias, entre ellas, el sistema educativo ${ }^{6}$, la agricultura, la policía, la seguridad interior, la legislación municipal, la cultura-aunque con ciertos límites derivados de una posible intervención federal a través de las tareas comunes-, etc. Con la reforma constitucional de 2006 las competencias legislativas exclusivas de los Länder han sido ampliadas, al sumárseles materias antes concurrentes ${ }^{7}$, así como algunas de las competencias marco ${ }^{8}$ que han pasado a ser exclusivas de los Länder. Además, siempre que ostenten la titularidad de la competencia legislativa, los Länder podrán concertar tratados con Estados extranjeros, siendo necesario al respecto el consentimiento del Gobierno Federal (art. $32 \mathrm{LF).}$

Las reglas constitucionales de reparto competencial han favorecido que en la praxis constitucional se haya experimentado una clara tendencia centralizadora de la Federación, de forma que la esfera federal ha asumido la responsabilidad de la regulación de las materias

\footnotetext{
$\overline{{ }^{6}}$ Tras la reforma de 2006, Los Länder han asumido la plena responsabilidad no sólo, como hasta ahora, en el ámbito escolar, sino también en la formación universitaria. Aunque los organismos universitarios y de investigación científica seguirán contando con el respaldo financiero de la Federación y, por ende, con injerencias estatales.

${ }^{7}$ Las materias antes concurrentes que han pasado a ser exclusivas de los Länder son: ejecución penal y prisión preventiva; derecho de reunión; centros geriátricos y de acogida; horarios de comercios; establecimientos de restauración, salones creativos, ferias, exposiciones y mercados; concentración parcelaria; mercado inmobiliario rural y arrendamientos rústicos; vivienda, excepto subvenciones y ayudas para acceder a la vivienda, primas a la construcción de viviendas y construcción de viviendas para mineros; y la lucha contra el ruido provocado por instalaciones dedicadas al ocio o con fines sociales.

${ }^{8}$ Las competencias marco que han pasado a la competencia exclusiva de los Länder son: el régimen jurídico de los funcionarios públicos, incluyendo a jueces y funcionarios judiciales; la normativa sobre centros de enseñanza superior, excepto la relativa al acceso y fin de los estudios que será competencia concurrente, y el régimen jurídico de la prensa.
} 
más importantes y de mayor trascendencia política. Tendencia reforzada por la cláusula de prevalencia ex art. $31 \mathrm{LF}$, en virtud de la cual el Derecho Federal prima sobre el Derecho de los Länder. A la ampliación de la esfera de actuación federal han contribuido las llamadas tareas comunitarias previstas en el art. 91 LFB, que han modulado el esquema inicial de reparto competencial esbozado en la Constitución, porque al amparo de las mismas el Bund, al financiar parte de las actuaciones de los Länder, ha condicionado la actuación de éstos, los cuales han visto recortada su autonomía. De ahí que las tareas comunitarias hayan sido otra de las cuestiones abordada por la reforma de 2006, que ha reducido el peso de las tareas comunes del art. 91.A LF y reformulado las actuaciones conjuntas del art. 91.B LF.

Mediante las tareas comunes obligatorias del art. 91.a) LF el Bund participa en cometidos administrativos de responsabilidad de los Länder en los supuestos legalmente establecidos. Estas tareas comunitarias están referidas a determinados sectores, sobre los que los Länder tienen competencias, siempre que sean importantes para la colectividad federal y que precisen de la cooperación de la Federación para la mejora de las condiciones de vida; en concreto, la mejora de las estructuras económicas regionales, las estructuras agrarias y la protección de las costas ${ }^{9}$. Estas tareas requieren el dictado de una ley federal, que cuente con el consentimiento del Consejo Federal (Bundesrat), en la que se concreten las tareas comunes, los principios generales a los que ha de ajustarse su cumplimiento o ejecución y la determinación de las contribuciones económicas respectivas.

La otra fórmula comprende las tareas comunes potestativas del art. 91.b), que se limita a autorizar la conclusión de convenios de cooperación entre la Federación y los Estados Miembros sobre instalaciones y proyectos de investigación científica no universitarios, proyectos de investigación científica en Universidades, edificios para la investigación y la elaboración de estudios sobre la situación de la enseñanza en el plano internacional, siempre y cuando tengan un alcance suprarregional. En los dos primeros casos la cooperación depende de que se alcance la unanimidad de todos los Länder, de modo que cualquiera de ellos podría impedir la colaboración del Bund en este ámbito. En cuanto al reparto de los gastos, como los demás términos del acuerdo, se regulará en el correspondiente convenio.

Pero si en la esfera legislativa el grado de centralización es bastante elevado, dadas las amplias competencias legislativas federales, la balanza se inclina a favor de los Länder en la fase de aplicación de las leyes, incluida la legislación federal, donde los Länder tienen un peso preponderante, como corresponde a un "federalismo de ejecución". Los Estados concentran la mayor parte de la capacidad administrativa, representando la competencia federal administrativa una excepción, prevista de forma expresa en la Constitución. Materias reservadas a la Administración Federal son las fuerzas armadas, las finanzas federales, el tráfico aéreo y ferroviario, la policía federal (arts. 8390 LF). Por ende, la administración está casi totalmente en manos de los Länder. La amplia actividad ejecutiva de los Länder "conlleva un grado de decisión política no despreciable, y permite además la adaptación de las leyes federales, en su aplicación, a las concretas necesidades y peculiaridades de cada Land" (Sánchez, 1997, p. 53).

Con carácter general Los Länder ejecutan las leyes federales como asunto propio, al estar facultados para desarrollarlas reglamentariamente conforme a su identidad y características (art. 84.1 LF). Al respecto estos pueden dictar las normas necesarias sobre autoridades y

\footnotetext{
${ }^{9}$ Con anterioridad a la reforma constitucional de 2006 se incluía también como tarea común la construcción y ampliación de universidades, incluyendo clínicas universitarias. Con su supresión, esta materia pasa al ámbito competencial exclusivo de los Länder, lo que no imposibilita para que, en el caso de que la construcción o ampliación de la Universidad tenga un alcance supraregional, pueda actuarse esta competencia como una tarea comunitaria del art. 91.B LF, pudiendo así obtener financiación del Bund.
} 
procedimiento administrativo, apartándose de lo dispuesto en esta materia por la legislación federal, salvo casos muy excepcionales, en los que, en contrapartida, se requerirá el consentimiento del Bundesrat para aprobar la ley federal. Si algunos Länder ejercitaran su derecho de apartarse de la normativa federal inicial, una posterior norma federal que regulara la cuestión no entraría en vigor en tales Länder al menos hasta seis meses después de su promulgación, de forma que los mismos tengan un margen para reaccionar. Antes de la reforma del 2006 esta facultad legislativa de los Länder estaba condicionada a que la ley federal, que requería necesariamente la aprobación del Consejo Federal, no dispusiese otra cosa. Con la nueva redacción dada al art. 84 LF se ha pretendido, como más abajo se indica, recortar la intervención de la Federación en la organización de los Länder cuando éstos desarrollan leyes de la Federación y, especialmente, reducir los supuestos en los que se requiere el consentimiento del Bundesrat, ya que la intervención del Bundesrat en la legislación federal al amparo del art. $84 \mathrm{LF}$ ha sido excesiva, aproximadamente más de dos tercios de los casos en los que tal consentimiento es requerido.

Sin embargo, en ciertos casos, los Länder aplican las leyes federales por delegación del Bund, actuando como meros agentes de éste. La Federación está dotada de una serie de facultades con el fin de supervisar la correcta aplicación del derecho federal por los Länder. Los instrumentos para ejercer esta vigilancia federal están previstos en el propio ordenamiento constitucional y consisten para el caso de que los Länder ejecuten las leyes federales como materia propia en el envío de comisionados ante las autoridades supremas de los Länder y ante otros organismos subordinados; en este segundo caso, con el consentimiento de aquéllos o, si se negara, con el del Consejo Federal. En el supuesto de que las ejecuten por delegación del Bund, ante la posibilidad de dar instrucciones a las autoridades del Estado y exigir informes y la presentación de expedientes, así como enviar comisionados a todas las autoridades de los Länder. Por último, en las materias de su competencia exclusiva, las leyes de los Länder serán ejecutadas exclusivamente por ellos mismos.

En líneas generales, se trata de un federalismo relativamente equilibrado, donde los Länder han ejercido sus funciones de gobierno en el ámbito de sus competencias sin incurrir en prácticas de subordinación al Estado federal, o en intentos de obtención de mayores márgenes de autonomía, y donde las principales decisiones políticas han sido adoptadas conjuntamente entre el nivel federal y las entidades federadas (Politikverflechtung). No obstante, un alto porcentaje de competencias legislativas se sustrajeron progresivamente a los Länder, siendo absorbidas tanto por la Federación como por la Unión Europea, y en el ámbito de sus propios campos competenciales, éstos han tendido a consensuar una legislación uniforme, por ello, se ha hablado de tres tendencias en el campo legislativo alemán. La primera, la supranacionalización, común a los Estados integrantes de la Unión Europea, deriva de la importancia creciente del Derecho Comunitario Europeo que va desplazando progresivamente a las Leyes nacionales. La segunda, la centralización, deriva de la ampliación de las competencias legislativas de la Federación, a través de la reforma constitucional (centralización abierta) o mediante el agotamiento al máximo de las competencias legislativas federales en el campo de la legislación concurrente y de la legislaciónmarco (centralización encubierta). Este efecto reductor ha sido compensado, como se comentará más adelante, mediante la participación del Bundesrat en el procedimiento legislativo federal. En cualquier caso, a la concentración de competencias al amparo de la legislación marco se ha puesto fin con la desaparición de la misma en la última reforma. Por último, la unificación, alude a la tendencia legislativa manifestada a través del concierto de los Länder para legislar sobre determinadas materias, creando conjuntamente proyectos-tipo de ley.

Otro aspecto de gran importancia en materia competencial es el relativo a la intervención del 
Bundesrat en el proceso de elaboración de las leyes federales. El Parlamento alemán se compone de dos Cámaras: el Bundestag o Dieta Federal, cuyos diputados son elegidos por sufragio universal y el Bundesrat o Consejo Federal, a través del cual los Estados miembros colaboran en las tareas legislativas y administrativas de la Federación y participan en la decisión de los asuntos de la Unión Europea. El Bundesrat está conformado por sesenta y nueve miembros, repartidos entre los Länder en función del número de habitantes del mismo. A tal respecto todo Estado o Land tendrá, como mínimo, tres votos; los Estados con más de dos millones de habitantes tendrán cuatro, los de más de seis millones de habitantes, cinco votos y los de más de siete millones de habitantes seis votos. Son designados por los diferentes gobiernos de cada Land. Cada Estado podrá enviar tantos miembros como votos tenga, quienes están vinculados por un mandato imperativo y dependiente de los Gobiernos de los Estados, de forma que los votos de un Estado sólo se podrán emitir en bloque, respetando las instrucciones dadas por los Gobierno respectivos (art. 51 LF).

El Bundesrat constituye una pieza clave para el armonioso funcionamiento de este sistema y una vía para la participación de los Länder en la política federal. En tal sentido, todas las leyes aprobadas por el Bundestag han de ser enviadas al Bundesrat, cuya facultad de codecisión en el ámbito de la legislación nacional se traduce o bien en aprobar obligatoriamente las leyes (leyes de aprobación) o bien en interponer un veto que el Bundestag puede rechazar por idéntica mayoría (leyes de veto). Respecto a las primeras, el Bundesrat dispone de un poder de veto absoluto, ya que si rechaza el proyecto de ley federal éste decae (Zustimmungsgesetze). Se trata de todas aquellas leyes para las que la Ley Fundamental haya previsto de forma expresa la necesidad de aprobación explícita por ambas cámaras, lo que dilata el trámite legislativo, sobre todo cuando frente a una mayoría política en el Bundestag se opone otra de signo contrario en el Bundesrat. Por el contrario, cuando se trata de un texto legislativo que no exige su conformidad, el Bundesrat solamente tiene un veto parcial (Einspruchsgesetze), podrá interponer una impugnación, que es superable por la Dieta Federal por mayoría absoluta, en el caso de que el Bundesrat haya presentado el veto (sólo) por mayoría de sus votos, o por una mayoría de dos terceras partes si el Bundesrat ha decidido el veto con al menos dos tercios de los votos.

Si bien, en los primeros años de la República tan sólo un $10 \%$ de las leyes requerían la doble aprobación; en concreto, aquellas que afectaban de forma especial a los intereses de los Länder, posteriormente más del $60 \%$ de los proyectos de ley federal se encontraban sujeto al consentimiento expreso del Bundesrat, lo que ralentizaba y dificultaba la actividad legislativa federal e incluso, en ocasiones, quedaba bloqueada, bloqueo que se veía propiciado por los crecientes conflictos partidistas de los últimos años. Se trataba de una de las principales deficiencias del sistema federal, por cuanto

(...) el elevado número de leyes sobre las que el Bundesrat debía pronunciarse y los efectos de ello sobre el proceso legislativo había llevado cada vez más a percibir a dicha cámara como un factor de obstaculización del funcionamiento del federalismo, más que como una institución de aseguramiento de la posición de los Länder, pues estos con frecuencia votaban en función de intereses de partido y de la voluntad de apoyar o erosionar, según el caso el Gobierno federal. (Cabellos, 2006, p. 13).

A esta problemática ha pretendido hacer frente la Ley de reforma constitucional de 2006 reduciendo el número de proyectos de ley federales necesitadas del asentimiento del Bundesrat de casi un $70 \%$ a un $35 \%$ o $40 \%$, en contrapartida, al aumento de las facultades legislativas de los Länder. Con la renuncia por 
parte de los Estados federados a buena parte de sus derechos de veto en el Consejo Federal, el Bund saldrá fortalecido y se agilizarán los cambios legislativos, al evitarse la situación, cada vez más usual, de bloqueo en la tramitación de las leyes federales, que paralizaban la puesta en marcha de importantes proyectos en el país. Su consentimiento se seguirá requiriendo para la aprobación de leyes que supongan deberes para los Länder, que impliquen la realización de gastos o la asunción de deudas por parte de éstos.

Por su parte, el Tribunal Constitucional Federal (Bundesverfassungsgericht) es la institución que resuelve los posibles conflictos entre la Federación y los Länder, así como los que surjan entre los diferentes Länder. Se compone de dieciséis magistrados elegidos, ocho por el Bundestag y otros ocho por el Bundesrat, por mayoría cualificada. La participación del Consejo Federal alemán en la designación de la mitad de los magistrados constitucionales federales, no asegura, en la práctica, una adecuada representación de los Estados Miembros en la composición del Tribunal, ya que la elección de los candidatos entre juristas es ejercida por los partidos políticos nacionales que siguen una lógica parlamentaria y no territorial.

La experiencia alemana resulta interesante, por cuanto constituye un buen ejemplo de que una estructura federal no riñe con la existencia de un grado de igualdad entre los ciudadanos y con una considerable homogeneidad territorial en el nivel de prestación de los servicios y en el desarrollo económico ${ }^{10}$. Los principios de cooperación y de solidaridad son dos pilares básicos del federalismo alemán.

La praxis política del federalismo cooperativo en Alemania conllevó, entre otros efectos, una fuerte tendencia a la uniformidad federal de la legislación y, con ello, a un recorte considerable del pluralismo del Estado Federal. Lo que le valió la calificación de Estado federal-unitario, que alcanzaría su apogeo a finales de los ochenta. Sin embargo, tras el proceso de reunificación alemana se comenzaron a poner de relieve algunas deficiencias del sistema cooperativo. $\mathrm{La}$ última reforma constitucional ha pretendido corregir algunas de las disfunciones y problemas que se detectaron.

Aunque resulta muy aventurado emitir una valoración profunda de la $52^{\text {a }}$ Ley de reforma constitucional, puede concluirse que se ha logrado el objetivo propuesto de efectuar una delimitación más nítida de los ámbitos de competencia del gobierno federal y de los gobiernos estatales, reduciendo los casos de compartición competencial y de financiación mixta Bund-Länder, que habían favorecido la intromisión de la Federación en ámbitos competenciales reservados a los Länder y contribuido a diluir las responsabilidades de cada ente. Por su parte, los Gobiernos de los Länder han cedido la posibilidad de vetar las propuestas legislativas por mayores competencias en ámbitos tan importantes como el medio ambiente, la educación, el régimen de los funcionarios, etc.

Tales modificaciones han orientado el sistema federal hacia un modelo de federalismo de corte más competitivo, sin que hayan desaparecido por completo los elementos solidarios propios de un federalismo cooperativo, de lo que es fiel reflejo el mantenimiento de la estructura de la financiación de los Länder, que ha quedado pendiente de una reforma ulterior por falta del consenso necesario. Por ello, no se puede hablar tanto de un nuevo modelo de Estado Federal, que ha sido calificado por algunos autores como "Estado federal experimental", pero sí de su fortalecimiento.

\footnotetext{
${ }^{10}$ El Tribunal Constitucional alemán ha subrayado que el Estado Federal debe encontrar el ajustado equilibrio entre autonomía y el mantenimiento del carácter específico de los Länder de un lado, y del otro, una responsabilidad solidaria por la existencia y la autonomía de los otros Länder (BverfGE72, 330 (389))
} 
Las reglas de distribución de competencias en Austria:un federalismo unitario

El art. 2 de la Constitución Federal de 1929 en adelante CFA- consagra a la República de Austria como un Estado Federal compuesto por nueve Estados Autónomos independientes: Burgenland, Carintia, Baja Austria, Alta Austria, Salzburgo, Estiria, Tirol, Voralberg y Viena. A diferencia de otros modelos federales como EEUU, Suiza o Alemania, el modelo austriaco no surge a raíz de un pacto confederal de Estados Federados originarios preexistentes e independientes, sino a resultas de un proceso de descentralización de un Estado Unitario tras el final de la Primera Guerra Mundial. No obstante, el modelo federal austriaco es extremadamente centralizado, dada la extensión de los poderes de la Federación. El carácter atenuado del federalismo austriaco puede explicarse, entre otros factores, en el hecho de que la estructura federal austriaca fue una fórmula de compromiso entre los social demócratas, partidarios de un Estado central sobre la base de una autonomía administrativa local y los conservadores que respaldaban el proyecto de un modelo federal fundado sobre la soberanía originaria de los Estados, los cuales gozarían de una amplia autonomía respecto al nivel de gobierno central. Aunque finalmente se acogió la fórmula federal, las principales funciones y competencias recayeron en el Bund, al que se le reserva amplias posibilidades de intervención en múltiples sectores.

En virtud de la autonomía constitucional estatal, las Dietas Estatales pueden promulgar por sí mismas, por mayoría de dos tercios de los votos emitidos, y sin participación del legislador federal, las Constituciones Estatales con la única limitación de no contravenir la ley constitucional federal, cuya conformidad se encarga de garantizar el Tribunal Constitucional. Sin embargo, el margen de maniobrabilidad del poder constituyente estatal ha sido muy limitado debido a la detallada regulación que hace la Constitución Federal de la organización política interna de los Estados.
El orden constitucional austriaco resolvió el reparto de competencias entre ambos niveles de gobierno, el federal -Bund-y el estatal-Länder-, a través del método de la enumeración de las competencias federales y la cláusula residual de las competencias no enumeradas a favor de los Estados Autónomos. Dicha distribución de titularidades competenciales es bastante compleja, casuística y desequilibrada en beneficio de la Federación y en detrimento de los Estados Autónomos.

La Constitución federal austriaca contiene tres listas competenciales. La primera enumera las competencias federales exclusivas, en las que la legislación y ejecución son ejercidas por la Federación (art. 10). La segunda relaciona las competencias compartidas, esto es, aquellas en que la legislación es federal, pero corresponde la ejecución y responsabilidades administrativas a los Länder (art. 11). Por último, la tercera indica aquellas competencias en que la legislación de principios generales es federal, mientras que el desarrollo normativo y la ejecución es competencia estatal (art. 12). En el caso de que el Estado Federal no promulgara la ley-marco, los Länder son competentes para establecer sus propias leyes, estando obligados a modificarlas en un futuro para adecuarlas a un eventual marco legal.

La amplia regulación constitucional de las competencias a nivel federal, que asigna la mayoría y las más importantes funciones legislativas y ejecutivas a la Federación, así como la regulación excesivamente detallada de las leyes-marco, vacían, en cierta medida, de contenido la cláusula residual a favor de los Estados Autónomos (art. 15 CFA). Esta tendencia centralizadora se agrava por la previsión de instrumentos jurídicos que posibilitan la expansión de las competencias federales en determinados supuestos más allá del espíritu constitucional, como son la legislación federal de necesidad, cuando se considere que existe la necesidad de una normativa uniforme en determinados supuestos (arts. 10.1.15, 11.2, 11.5 
y 11.6 CFA) ${ }^{11}$; la devolución provisional de determinadas competencias del Land a la Federación cuando concurran ciertos requisitos (arts. 12.3, 15.6, 15.7 y 16 CFA) o la remisión de la regulación del sistema de financiación a una ley constitucional federal (art. 13).

Por último, los Estados Autónomos se encuentran sometidos a los dictados federales, a pesar de la ausencia de algún precepto constitucional donde se establezca y regule la superioridad de la ley federal sobre la estatal para resolver los supuestos de competencias concurrentes, con la única excepción del art. 99.1 CFA donde se establece la superioridad de la ley constitucional federal sobre la estatal.

Los Länder son responsables de la ejecución de un gran número de materias federales (administración federal indirecta o Mittelbare Bundesverwaltung). El art. 102.1 CFA prevé que los Gobernadores estatales sean los responsables de la ejecución de las competencias o funciones federales. Así el Gobernador Estatal es, por un lado, Presidente del Gobierno estatal, y políticamente responsable de él ante el Parlamento Estatal -Landtag-y, por otro, el más alto representante del Gobierno Federal en el Estado en calidad de administrador federal indirecto responsable de la ejecución de las políticas, directivas y leyes federales en el Estado Autónomo. En desarrollo de dicha función, los gobernadores estatales, los órganos administrativos subordinados a ellos, y los miembros de los gobiernos estatales, actuarán como autoridades ejecutivas de la Federación bajo la fiscalización del Tribunal Constitucional y sujetos a las instrucciones del Gobierno Federal o del Ministro Federal competente, o desde 2002, por los Tribunales Administrativos Independientes, según la respectiva materia.

Por otra parte, es importante resaltar la participación del Gobierno Federal en la adopción de las leyes estatales en forma de veto o acuerdo, ya que su aprobación resulta necesaria para la ley estatal que prevea para su ejecución el concurso de los órganos federales (art. 97.2 CFA). Además, el Gobierno Federal podrá, al mismo tiempo, vetar cualquier ley estatal aprobada por la Asamblea Estatal en el plazo de las ocho semanas siguientes a su remisión por el Gobernador al estimar que el texto perjudica los intereses de la Federación, aunque este veto federal puede ser superado por mayoría simple en la Dieta Estatal (art. 98 CFA).

Los Estados Autónomos pueden concertar convenios con otros Länder y/o con la Federación sobre materias de su respectivo ámbito de competencia (art. 15.a CFA), además de concertar tratados internacionales con Estados limítrofes de Austria, o bien con entes que los componen, como los cantones suizos. No obstante, el art. 16 CFA exige que el Gobernador del Estado informe previamente al Gobierno Federal antes del comienzo de las negociaciones sobre dichos tratados internacionales con el fin de obtener su consentimiento antes de que éstas concluyan. Corresponde al Presidente de la República, a propuesta del Gobierno Federal, y con el refrendo del Gobernador del Estado el otorgamiento de los poderes para el comienzo de las negociaciones y para la conclusión del tratado internacional. Estas cautelas se fundamentan en que los asuntos exteriores, en especial la conclusión de tratados internacionales, es una materia de competencia federal (art.10.1.2 CFA).

Por su posible incidencia en el nivel competencial también reviste importancia el Consejo Federal (Länderkammer), denominación que recibe la cámara alta austriaca, que junto con el Consejo Nacional (Nationalrat), conforman el Parlamento federal. El Consejo Federal actúa como cámara de representación territorial de los Estados federados. Sus miembros, que disponen de un mandato libre y

\footnotetext{
${ }^{11}$ De entre ellos, el que habilita a una intervención más amplia es el art. 11.2 CFA, al disponer que: "Se regularán por leyes federales, incluso en las materias en que la función legislativa corresponda a los Estados y en particular en el ordenamiento tributario, el procedimiento administrativo, las disposiciones generales del derecho penal administrativo, el procedimiento administrativo sancionador y la ejecución administrativa cuando se considere que existe necesidad de una regulación uniforme".
} 
representativo, son elegidos por los respectivos parlamentos de los Estados Autónomos (Landtage), variando el número de representantes por cada Estado en proporción a su respectiva población. Actualmente la cámara alta austriaca está compuesta de 64 miembros, frente a los 163 del Consejo Nacional, distribuidos de la forma siguiente: Austria Baja, 12 escaños; Austria Superior y Viena, 11 cada una; Estiria, 10 puestos; Carintia y Tirol, 5 cada una; Salzburgo, 4 escaños y, finalmente, Burgenland y Vorarlberg, 3 escaños cada una. Los escaños correspondientes se distribuyen, de modo proporcional, entre los partidos presentes en el Landtag. Normalmente se eligen parlamentarios allegados a los partidos nacionales mayoritarios lo que debilita la posición del Bundesrat como órgano de participación de los Länder.

Además el papel que el Consejo Federal ejerce como Cámara territorial dentro del sistema político austriaco es muy débil frente a la supremacía parlamentaria del Consejo Nacional. En la mayor parte de los casos el poder de veto del Consejo Federal frente a las leyes aprobadas por la cámara de representación general es suspensivo, porque, aunque es ejercitable sobre toda decisión legislativa, sea constitucional y ordinaria, no puede utilizarse para las leyes federales más importantes, y es fácilmente superable por el Consejo Nacional, al requerirse únicamente que éste reitere de nuevo la propuesta de ley por mayoría simple de votos en presencia de, al menos, la mitad de sus miembros. Únicamente está previsto el derecho de veto absoluto a favor del Consejo Federal cuando se trata de reformas constitucionales que afecten a la representación de los Estados en dicho Consejo, pues se requiere necesariamente la conformidad del Consejo y debe ser aceptada por la mayoría de los representantes de cuatro Estados federados como mínimo. Por último, cuando se trate de leyes federales que restrinjan las competencias de los Estados, se requiere necesariamente la presencia de la mitad los miembros del Consejo Federal y una mayoría de dos tercios de los votos emitidos.
En relación al Tribunal Constitucional federal (Verfassungsgerichtshof), órgano de resolución de los conflictos territoriales entre el Estado Federal y los Länder, está formado por veinte jueces, entre titulares y suplentes, nombrados por el Presidente de la República: once (presidente, vicepresidente, seis magistrados titulares más y tres suplentes) a propuesta del Gobierno Federal, y nueve a propuesta del Parlamento bicameral, en razón de tres miembros titulares cada Cámara, dos suplentes el Consejo Nacional y uno el Consejo Federal. Esta forma de designación, junto con el mandato representativo de los parlamentarios, refleja que la intervención de los territorios, vía Consejo Federal, en la elección de los magistrados del TC es bastante difusa, incluso más que en el supuesto alemán, representando no tanto a los Länder, como a las fuerzas políticas nacionales.

El federalismo austriaco también ha avanzado en la praxis por la vía cooperativa, como consecuencia de la importancia adquirida por los instrumentos de colaboración y coejercicio de competencias y los mecanismos de cooperación financiera, así como por el protagonismo de órganos, aunque desprovistos de cualquier fundamento constitucional, como la Conferencia de Presidentes de los Länder -que hace las veces de interlocutor político con la Federación, coordinando la política de los Länder- o la Conferencia de presidentes y de otros funcionarios de los Parlamentos de los Länder.

\section{La compleja delimitación competencial en} Bélgica: el federalismo doble

Tras un largo proceso de federalización, Bélgica se proclamó como Estado Federal a partir de la revisión constitucional aprobada el 5 de mayo de $1993^{12}$. El artículo 1 de la Constitución de 1994 afirma que Bélgica es un Estado federal

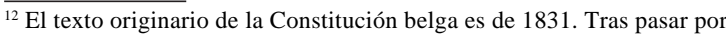
varias reformas, los cambios en el texto realizados en 1970, 1980, 1988 y sobre todo 1993, tenderían a federalizar el Estado. El 17 de febrero de 1994 se publicó la denominada "Constitución refundida", elaborada por las cámaras constituyentes, que unifica y sistematiza las anteriores reformas del texto constitucional, modificado por última vez en 2002.
} 
compuesto de Comunidades y Regiones, esto es, en este país se superpone un federalismo territorial, que se articula en regiones, y un federalismo personal, que se concreta en comunidades culturales, por lo que se ha calificado de federalismo doble. Esta singular organización federal es uno de los aspectos más originales del sistema federal belga, que pretende responder a la necesidad de articular una fórmula que resuelva la difícil convivencia de diversos grupos nacionales en el seno de esta federación, especialmente la tensa relación entre francófonos y flamencos, que aún hoy sigue provocando serios conflictos políticos.

Por lo que respecta a la delimitación competencial, la Constitución federal belga, a diferencia de la alemana y la austriaca, es muy escueta. Se limita a establecer unos principios o bases para la asignación de competencias entre federación, comunidades y regiones. Concretamente determina que la autoridad federal sólo tendrá competencias sobre las materias que formalmente le atribuya la Constitución y las leyes adoptadas en virtud de la misma, mientras que las competencias residuales, esto es, aquellas no encomendadas expresamente a la autoridad federal, corresponden a las entidades federadas -comunidades o a las regiones-. Dicha cláusula ha quedado, sin embargo, condicionada, en virtud de una disposición constitucional transitoria, a la aprobación de una ley federal que enumere las competencias exclusivas de la autoridad federal (art $35 \mathrm{CB})$.

Por tanto, mientras el art. 35 de la Constitución no sea ejecutado, dado que ni las comunidades, ni las regiones tienen la posibilidad de aprobar constituciones propias, que en derecho comparado son un útil instrumento que contribuye a la definición del cuadro competencial, son las leyes federales las que atribuyen las competencias de manera expresa a las Comunidades y Regiones a través de relaciones de carácter exhaustivo. Las competencias comunitarias y regionales son, por ello, competencias transferidas legalmente, correspondiendo las restantes competencias al
Estado Federal. No se contemplan competencias concurrentes, pero sí están previstas, en cambio, en el art. 137 de la Constitución, las reasignaciones de competencias entre la Región y la Comunidad, es decir, transferencias interfederadas. Así tal transferencia se ha producido de la región flamenca hacia la Comunidad flamenca, con la consiguiente simplificación en el ámbito institucional. Por último, cada colectividad política, federal o federada, dispone de una administración propia, correspondiendo la ejecución de las leyes federales al Gobierno federal, mientras que las leyes federadas competen a los gobiernos federados.

También a ambas colectividades se les reconoce un poder exterior, de forma que las Comunidades y las Regiones belgas han sido habilitadas para concluir tratados internacionales en materias comprendidas en sus competencias exclusivas; mientras que negocian, celebran y firman, en pie de igualdad, los tratados mixtos que tratan a la vez de materias federales, comunitarias o regionales. Pueden, igualmente, representar a Bélgica en las organizaciones internacionales.

Según el art. 2 del texto constitucional, Bélgica consta de tres Comunidades lingüísticas: la Comunidad Flamenca, la Comunidad Francesa y la Comunidad Germanófona. Cada comunidad tiene competencias en los territorios regionales donde es exclusiva la lengua que las define, si bien las comunidades francesa y flamenca tienen conjuntamente competencias en la Región bilingüe de Bruselas-Capital. Son competencias de las Comunidades las materias culturales (la defensa e ilustración de la lengua, las bellas artes, el patrimonio cultural, las bibliotecas, la casi totalidad de las competencias en materia de radio y televisión, turismo y deporte), la enseñanza (con exclusión de la fijación del año escolar obligatorio, los requisitos mínimos para la obtención de títulos, el régimen de salarios de los docentes), las materias personalizables (es decir, aquellas que tienen como destinatario directo a las personas, tales como la política de sanidad, la familiar, ciertos 
componentes de la política de asistencia social y la relativa a los jóvenes), la cooperación a nivel intercomunitario e internacional en aquellas materias en que las Comunidades sean competentes, incluida la conclusión de tratados. Excepto la Comunidad Germánica, a las otras dos comunidades también les compete regular el uso de las lenguas en las materias administrativas, en la enseñanza en los establecimientos creados, subvencionados o reconocidos por los poderes públicos y en las relaciones sociales, aunque la autoridad nacional se reserva competencias para reglar el uso de las lenguas en las comunas con estatus lingüístico especial y en los municipios de la Región de Bruselas-Capital.

Ha de reseñarse también que la Comunidad francesa transfirió el ejercicio de numerosas competencias a la Región Valona, a excepción de la cultura en sentido estricto, la radio y la televisión, la enseñanza y el empleo de las lenguas, así como a la Comisión Comunitaria francesa, compuesta por miembros francófonos del Consejo y del Gobierno de la Región de Bruselas de forma que, desde el 1 de enero de 1994, ejerce por vía de decretos las mismas competencias que la Comunidad francesa sobre el territorio de la región. Ello ha conllevado a que las Regiones valona y de Bruselas se consoliden en detrimento de una Comunidad francesa cuyas competencias disminuyen progresivamente. A ello debe añadirse que la comunidad cultural flamenca ha asumido las competencias de la Región de Flandes.

A su vez, Bélgica consta de tres regiones: la Región Valona, constituida por los territorios de lengua francesa y los de lengua alemana ${ }^{13}$, la Región de Flandes ${ }^{14}$, donde se habla el neerlandés, y la Región Bruselas-capital, en la que conviven francófonos y flamencos, en una proporción del $85 \%$ y del $15 \%$ respectivamente. Las competencias que tienen atribuidas a las regiones son las relativas al medio natural y al sector socioeconómico: el urbanismo y la ordenación del territorio, la protección del medio ambiente, la vivienda, la política de aguas, ciertos aspectos de la política económica, el comercio exterior, la política energética y agrícola, la tutela y financiación de los municipios y las provincias, el empleo, las tecnologías, la infraestructura, la red de comunicaciones y transportes, etc. También la Región de Bruselas-Capital ejerce, bajo la denominación de Comisión Comunitaria común, algunas competencias complementarias en materias personalizables, mediante decretos aprobados por mayoría doble de los grupos lingüísticos que existen en el seno del Consejo Regional.

La Constitución no establece ninguna jerarquía entre las normas de las colectividades federadas y aquellas de la entidad federal. Los decretos comunitarios y regionales tienen fuerza de ley, así como las ordenanzas municipales de la Región de Bruselas-Capital, si bien poseen un rango ligeramente inferior al de las leyes aquellas que intervienen en ámbitos particulares, como las de ordenación del territorio o el urbanismo.

También las Comunidades y las Regiones belgas han sido habilitadas para concluir tratados internacionales en materias comprendidas en sus competencias exclusivas; mientras que negocian, celebran y firman, en pie de igualdad, los tratados mixtos que tratan a la vez de materias federales, comunitarias o regionales. Pueden, igualmente, representar a Bélgica en las organizaciones internacionales.

En relación a la segunda Cámara parlamentaria de representación de los Estados, ha de resaltarse que el Senado belga no se ajusta plenamente ni en su composición, ni en sus competencias al perfil de Cámara de Representación territorial propia de un sistema federal.

Por un lado, tiene una peculiar composición, prevista en los arts. 67 y 68 de la Constitución, que persigue una representación proporcional de las comunidades lingüísticas, lo que, en

\footnotetext{
${ }^{13}$ La región valona comprende las siguientes cinco provincias: Brabante Valón, l’Hainaut, Lieja, Luxemburgo y Namur.

${ }^{14}$ La región flamenca está integrada por las provincias de Amberes, Brabante flamenco, Flandes occidental, Flandes oriental y Limburgo.
} 
contrapartida, ha conllevado una tímida representación de los intereses territoriales al no estar representadas las regiones en el seno de la Alta Asamblea. Se compone de un total de 71 senadores distribuidos entre los grupos lingüísticos: 41 miembros pertenecen al grupo lingüístico neerlandófono, 29 al grupo francófono y 1 designado por la Comunidad germanófona. En cuanto a su forma de designación, han de distinguirse fundamentalmente dos categorías: los senadores comunitarios y los senadores nacionales. Los primeros, los senadores comunitarios, que representan a las Comunidades, son un total de 21, de los que diez delegados son electos por el Consejo flamenco, otros diez por el Consejo de la Comunidad francesa y 1 designado por el Consejo de la Comunidad Germana. De esta forma, las regiones indirectamente también están representadas en cierta medida, ya que el Consejo flamenco y el Consejo de la Comunidad francesa, que los designan, están compuestos, de hecho, por miembros elegidos directamente por los Consejos Regionales ${ }^{15}$. Los segundos, los senadores nacionales, un total de 40 son elegidos de forma directa 25 por un colegio electoral neerlandés y 15 por un colegio electoral francés. Por último, los 40 senadores nacionales y los 21 senadores comunitarios cooaptan un tercer grupo de 10 senadores, entre los que debe haber seis neerlandófonos y 4 francófonos (senadores cooptados). Además, se exige que los 70 senadores francófonos y neerlandófonos, 7 al menos deben estar domiciliados en la Región de Bruselas capital el día de su elección; y a su vez que cada una de las diez provincias belgas ${ }^{16}$ debe contar, por lo menos, con un representante entre los 71 senadores. La complejidad de la composición del Senado belga, se completa con la categoría de los senadores por derecho, que la componen los hijos del Rey, si han cumplido los dieciocho años, si bien no disponen de voz deliberativa hasta los veintiún años y no se tienen en cuenta para la determinación del quórum de presencias.

En relación a las competencias del Senado, éstas son limitadas por cuanto: por un lado, no ejercita el control sobre el Gobierno federal, cuyos miembros son responsables únicamente ante la Cámara de Representantes; y, por otro, la mayor parte de las leyes federales es votada sólo por la cámara baja, mientras que la intervención del Senado es facultativa, por cuanto puede solicitar, a petición de un mínimo de quince de sus miembros, para su examen un proyecto o proposición de ley en el plazo de quince días siguientes a la recepción del proyecto. En tal caso, dispondrá de sesenta días para formular enmiendas, aunque la última palabra la tiene la Cámara de Representantes, que podrá aprobar o rechazar en todo o en parte las enmiendas aprobadas por el Senado. No obstante, se requerirá la aprobación de ambas Cámaras para la revisión de la Constitución y también para aquellos textos relativos a la estructura del Estado, en concreto para la adopción de las leyes relativas al reparto de competencias entre el Estado federal y las entidades territoriales, a la organización de juzgados y tribunales, al Consejo de Estado y a las relaciones internacionales del Bélgica, o que incluyan la aprobación de acuerdos de cooperación concluidos entre el Estado, las Comunidades y las Regiones. Además el Senado es el único competente para pronunciarse, por vía de dictamen motivado, no vinculantes, sobre los conflictos de intereses entre las distintas asambleas parlamentarias federales y federadas. De esta forma, pese a que el número de representantes de las entidades federadas (21 sobre 71) es muy modesto, las funciones atribuidas lo configuran

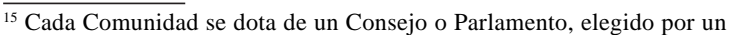
período de cinco años, sin posibilidad de disolución anticipada. El Consejo de la Comunidad Francesa no es elegido directamente, se compone de 94 miembros, 75 de los cuales serán los diputados electos del Consejo Regional Valón, elegidos directamente, y 19 de y entre los miembros francófonos del Consejo de la Región de Bruselas-Capital, que se reparten entre los grupos políticos en proporción al resultado de las elecciones. Por su parte, el Consejo flamenco ejerce simultáneamente las competencias comunitarias y las competencias regionales y, por tanto, tan sólo existen las instituciones de la Comunidad flamenca, que ha absorbido las instituciones de la región. El número de miembros de dicho Consejo asciende a 124: 118 elegidos directamente en la región flamenca, a los cuales se suman los seis primeros miembros electos del grupo lingüístico neerlandés del Consejo de la Región de Bruselas-Capital. Por último, la pequeña Comunidad germanófona consta de un Consejo compuesto de 25 miembros elegidos directamente por los ciudadanos belgas domiciliados en una de los municipios de la región de lengua alemana.

${ }^{16}$ Las provincias de Bélgica son diez: Amberes, Brabante Flamenco, Brabante Valón, Flandes Occidental, Flandes Oriental, Henao, Lieja, Limburgo, Luxemburgo y Namur. A éstas hay que agregar la región capital de Bruselas.
} 
como un foro importante para el diálogo entre la Federación, las Comunidades y las Regiones.

La solución de conflictos entre el Estado, las Comunidades y las Regiones compete a la Corte de Arbitraje. También en esta institución, formada por doces jueces, se ha procurado el equilibrio entre flamencos y francófonos, de forma que comprende seis jueces de habla francesa y seis jueces de habla neerlandesa. Si bien, en aras de asegurar la representación del grupo germanófono, uno de los jueces ha de demostrar un conocimiento suficiente del alemán. El nombramiento de dichos jueces tiene carácter vitalicio y corresponde al Rey, quien, en el supuesto de producirse una vacante, elige entre una lista doble que le es presentada por el Senado o por la Cámara de Representantes de forma alternativa. Las Cámaras aprueban dichas listas por una mayoría de dos tercios de los miembros presentes en la votación. El Tribunal anula las leyes, decretos o reglamentos que invaden las competencias legislativas del Estado federal o de una de las colectividades federadas.

Este complejo entramado territorial, que aspira adaptar las estructuras del Estado a la diversidad nacional, ha forzado al fortalecimiento, en aras de un funcionamiento armónico, de los principios de lealtad federal, reconocido en el art. 143 de la Constitución belga, y de cooperación entre las colectividades territoriales superpuestas. Por tal razón, se han puesto en marcha formas de colaboración no reguladas constitucionalmente, entre las que destaca especialmente el Comité de Concertación. Dicho Comité está compuesto de seis ministros federales -entre los que se encuentra el primer ministro, quien ostenta la presidencia$\mathrm{y}$ otros seis que representan a los gobiernos regionales y comunitarios. Este Comité está encargado de la prevención de conflictos de intereses entre el poder federal y las diferentes entidades federadas y de la resolución de los problemas de coordinación general que plantean sus políticas respectivas, debiendo adoptar sus decisiones por unanimidad.
En definitiva, en Bélgica el federalismo se encuentra en evolución, en búsqueda constante de un equilibrio entre unidad y diversidad. Con un sistema federal único se persigue proteger la identidad de tres grupos lingüísticos, dotándoles de un alto nivel de autonomía política, económica y cultural. Pese a tales intentos por preservar un sistema territorial cohesionado, la estructura federal belga se encuentra amenazada por un proceso segregacionista y centrífugo, que pudiera provocar la desmembración del Estado y la consiguiente constitución de dos nuevas entidades estatales.

\section{El orden competencial en la Confederación suiza: un federalismo equilibrado}

Aunque continúa llamándose oficialmente confederación, Suiza es un Estado federal compuesto de veintiséis cantones, denominación que reciben los Estados miembros de la Federación Suiza, que se remonta a 1848. El artículo primero de la Constitución del 2000 indica que la Federación helvética la forman los cantones de Zurich, Berna, Lucerna, Uri, Schwyz, Obwald, Nidwald, Glaris, Zug, Friburgo, Solothurn, Ciudad de Basilea, Comarca de Basilea, Schaffhausen, Appenzell Outer-Rhoden, Appenzell InnerRhodes, Sankt Gallen, Grisones, Argovia, Turgovia, Ticino, Vaud, Valais, Neuchâtel, Ginebra and Jura ${ }^{17}$. La creación o supresión de un cantón requiere una revisión constitucional y, en consecuencia, la aprobación expresa del cuerpo electoral y de los cantones ${ }^{18}$.

\footnotetext{
${ }^{17}$ Los cantones se caracterizan por su gran diversidad política, cultural y especialmente lingüística. Así en 17 cantones el alemán es la lengua predominante; cuatro cantones -Ginebra, Vaud, Neuchâtel y Jura- son francófonos; los cantones de Berna, Friburgo y Valais son bilingües -se habla el francés y el alemán-; mientras que Tesino es el único cantón en el que se habla únicamente el idioma italiano, aunque en el sur de Grisones, cerca de la frontera con Italia, también predomina el italiano. Por último, el cantón Grisones es plurilingüe, al hablarse el alemán, italiano y el idioma retorromano o romanche. Las cuatro lenguas nacionales -alemán, francés, italiano y retorromanche- están protegidas por la Constitución, aunque la última es hablada por una minoría muy escasa.

${ }^{18}$ Así, por ejemplo, el 24 de septiembre de 1978, el pueblo suizo se expresó favorablemente al nacimiento del nuevo cantón del Jura, que se independizó del cantón de Berna.
} 
En virtud de la aplicación del principio federal, los cantones son soberanos y, por tanto, disponen de autonomía constitucional, si bien, esta autonomía está limitada por la Constitución federal y sujeta a dos condiciones que garantizan su carácter democrático: que el texto constitucional sea aprobado en referéndum por el pueblo cantonal y que establezca la iniciativa popular para la reforma constitucional. Las Constituciones cantonales serán garantizadas por la Confederación, mediante su Asamblea Federal, siempre que no contengan estipulaciones contrarias al derecho federal (arts. 51 y 172.2 CS).

La Constitución Federal establece las competencias de la Federación, pero las atribuciones de la Federación no son estrictamente las que derivan de los enunciados expresos, sino que comprenden también las facultades implícitas que se derivan de aquellos, cuando resulten necesarias para obtener las finalidades inherentes a las competencias explícitamente mencionadas en el texto constitucional. Esta cláusula de los poderes implícitos, aunque no alcanza la importancia que reviste en el federalismo norteamericano, ha reforzado a la Federación. Además el ámbito de los poderes delegados a la Federación es sumamente amplio, como consecuencia del incesante proceso de centralización política llevado a cabo a través de numerosas reformas constitucionales, dirigidas, principalmente, a aumentar las competencias de la Federación en todas aquellas materias que requieren una regulación uniforme. Entre esas reformas parciales, la más profunda fue la de 1947, que permitió a la Federación influir directamente en la economía suiza, consagrando un régimen de intervencionismo federal.

Por su parte, los cantones ejercen todas aquellas competencias que no han sido delegadas constitucionalmente a la Federación (art. 3 CS). Aunque en la nueva Constitución de 2000 se alude a algunas competencias cantonales, no tienen carácter constitutivo, son meramente citadas a efectos de delimitar con más exactitud las competencias federales, por cuanto sus competencias son residuales, en el sentido de que no están relacionadas ni en la Constitución federal, ni en las Constituciones cantonales, estas son simplemente deducidas, a sensu contrario, de la lista de competencias federales.

En términos generales, la Federación suiza tiene actualmente competencia exclusiva sobre las siguientes materias: la política exterior, la declaración de la guerra y la firma de la paz; la representación diplomática; la protección civil; la legislación sobre organización militar y armamento; la política monetaria; la legislación sobre todas aquellas materias que tienen aplicación en varios cantones: transportes, carreteras, sanidad, extranjería, derecho civil, derecho penal, etc. Por otra parte, están las competencias compartidas, donde a la Confederación tan sólo le corresponde la regulación de los principios más fundamentales, y las concurrentes, es decir, aquellas que pueden entrar en la esfera de la Federación si ésta así lo decide por entender que es conveniente una normativa uniforme -previsión introducida en la reforma de 1999 en el art. 42.2. CS-. Esta última forma de competencia implica que la legislación cantonal permanece en vigor hasta que la Confederación hace uso de su competencia.

Por otra parte, tras la última revisión constitucional, a los cantones se les permite la conclusión de tratados internacionales en el ámbito de sus competencias, previa información a la Federación, mientras no sean contrarios al derecho o a los intereses de la Confederación o al derecho de otros cantones. Tal reconocimiento les permite desarrollar también una política exterior propia. Contra los tratados intercantonales o aquellos negociados por un cantón con otro Estado, podrán presentar reclamación el Consejo Federal o cualquier otro cantón, y, en tal caso, el tratado deberá ser aprobado por la Asamblea Federal.

El art. 49 de la Constitución Federal declara expresamente la primacía del derecho federal sobre el derecho cantonal contrario (constitucional y ordinario), regla que ha sido afirmada desde 1848 por la jurisprudencia del Tribunal Federal. 
Por último, a los cantones, como es propio de un federalismo de ejecución (Vollzugsföderalismus), corresponde la aplicación tanto de las leyes federales como cantonales. La administración propia federal tiene una importancia escasa en algunos sectores muy concretos, como el militar, la educación, las aduanas, los correos, los ferrocarriles o del seguro público contra accidentes.

Los cantones pueden estipular en sus ámbitos de competencias tratados entre sí, que no sean contrarios a los intereses federales ni a los derechos de otros cantones, debiendo notificar de su conclusión a la Federación, así como crear organizaciones e instituciones comunes para satisfacer intereses regionales recíprocos. Tales tratados intercantonales que, por regla general, suelen concernir a algunos cantones, y no a todos ellos, se llaman concordatos. Todo concordato intercantonal está sometido al derecho federal, debiendo ser ratificado por los Parlamentos de los cantones implicados, así como por la autoridad federal, que avala así su conformidad al derecho federal. Son susceptibles de recurso ante el Tribunal Federal.

Igualmente, como es característico de un Estado Federal, existe una segunda Cámara parlamentaria (Consejo de Estados), que representa a los cantones. La Asamblea Federal, la más alta autoridad de la Federación suiza, está conformada por dos cámaras: por un lado, el Consejo Nacional o Cámara popular, compuesto de doscientos diputados elegidos directamente por el pueblo y conforme a un sistema de representación proporcional y repartidos teniendo en cuenta el número de habitantes de cada cantón, que actúa como circunscripción electoral; y el Consejo de Estados o Senado, compuesto por cuarenta y seis delegados de los cantones. Los subcantones de Obwald, Nidwald, Basle-City, Basle-Land, Appenzell Outer-Rhodes y Appenzell Inner-Rhodes eligen cada uno a un senador, mientras que a los otros cantones les corresponde elegir a dos senadores, quedando reservado a cada cantón el procedimiento de elección. Al respecto, en todos los cantones se ha optado por una elección popular directa, mediante un sistema electoral mayoritario, excepto en el cantón de Jura. El Consejo de Estados posee amplias facultades en el procedimiento legislativo, por cuanto se está ante un bicameralismo perfecto, de forma que se requiere siempre su aprobación, con independencia de la materia que aborde la ley en tramitación.

En relación al Tribunal Federal, se compone actualmente de treinta jueces elegidos por la Asamblea Federal, en sesión conjunta de ambos Consejos, que deberá velar para que las diversas lenguas oficiales estén representadas por los mismos. Es el Tribunal Federal, autoridad judicial suprema de la Confederación, el órgano competente para la resolución de litigios entre cantones o entre la Federación y los cantones. Carece, sin embargo, de la facultad de controlar la constitucionalidad de las leyes federales, aunque invadan el ámbito competencial reservado, pero sí es competente para declarar la inconstitucionalidad del derecho cantonal.

Al igual que el sistema alemán, el federalismo suizo ha evolucionado progresivamente hacia un federalismo cooperativo, lo que se refleja en el deber de lealtad federal (Bundestreue), que obliga a los Cantones, además de a las autoridades centrales, a tener en cuenta, en el ejercicio de sus respectivas competencias, los intereses comunes, a colaborarse y ayudarse recíprocamente, o el derecho al auxilio financiero de la Federación, a la que le compete promover la igualdad financiera entre cantones; así como en la existencia de órganos de concertación, como las Conferencias intercantonales especializadas o la Conferencia de los Gobiernos cantonales.

Las primeras, las Conferencias intercantonales, reúnen periódicamente a los Ministros cantonales para coordinar y armonizar sus actividades en la materia específica que les concierne. Estas Conferencias revisten una importancia particular en los ámbitos donde la soberanía ha sido ampliamente cantonal, así en materia de educación (armonización de los 
calendarios, programas y sistemas escolares, equivalencia de las formaciones, etc.). Las mismas también son un foro utilizado para armonizar las posiciones de los Cantones sobre un asunto particular a fin de defender una opinión común frente a la Confederación.

La segunda, la Conferencia de los Gobiernos cantonales, fue creada por una Convención firmada el 8 de octubre de 1993 entre todos los Cantones. Está integrada por todos los ejecutivos cantonales, representado cada uno por un Ministro, y se reúne cuatro veces al año en asamblea plenaria. Su funcionamiento es financiado plenamente por los Cantones, proporcionalmente a su número de habitantes. Más allá de la política exterior y los asuntos europeos, esta Conferencia está activa igualmente en las materias clave del reparto financiero y de la reforma del federalismo suizo. El Gobierno suizo (Consejo federal) es invitado a participar en las sesiones, pudiendo hacer propuestas allí.

Pero el instrumento fundamental de concertación, como ya se ha comentado, siguen siendo los concordatos intercantonales, convenios firmados por dos o más cantones para regular sus relaciones en el ámbito de sus competencias (como asistencia judicial, prohibición de ventajas fiscales, creación de Escuelas Superiores, etc.).

En esta línea de profundizar en el federalismo cooperativo, los ciudadanos suizos aprobaron mediante referéndum, el 28 de noviembre de 2004, un paquete de veintisiete reformas a la Constitución suiza, que supondrán un avance muy importante del federalismo suizo. Este proyecto, entre otras medidas, persigue una más adecuada delimitación de las tareas de la Confederación y de los cantones conforme al principio de subsidiariedad, establece la necesidad de colaboración entre cantones en nueve áreas e introduce un nuevo sistema de ajuste fiscal que otorga más fondos a los cantones financieramente débiles para posibilitarles la prestación de un nivel básico de servicios públicos, reduciendo así las diferencias intercantonales. No obstante, este nuevo sistema no entrará en vigor hasta el primero de enero de 2008. Lo que refleja una vez el ritmo pausado de evolución tan característico de la estructura federal suiza.

La redistribución de competencias, núcleo gordiano de la cuestión territorial colombiana

Con este artículo no es mi intención, en modo alguno, defender implícitamente la federalización de Colombia, pero sí la necesidad de que el Estado Colombiano integre algunas técnicas propias del federalismo, aunque no asuma en el futuro formal y expresamente el modelo federal. En concreto, tres son las tareas ineludibles en todo Estado que, como Colombia, pretenda ahondar y avanzar en el sendero de la descentralización política:

- $\quad$ La regulación de una nítida delimitación de competencias, pero articulando fórmulas y mecanismos de cooperación;

- La configuración de una Cámara parlamentaria de carácter territorial, adaptada a las peculiaridades territoriales, culturales, étnicas, históricas y económicas del país, que sea un cauce eficaz donde las entidades territoriales intermedias puedan canalizar su voz y hacer valer sus intereses en la elaboración y aprobación de las leyes de la República y en la adopción de las decisiones generales;

- Yla constituciónde un órgano jurisdiccional independiente encargado de la resolución de los conflictos territoriales.

Al respecto, las fórmulas utilizables son múltiples y bastante heterogéneas, como se pone de manifiesto en las muy diversas soluciones adoptadas por los países que han sido objeto de estudio. Si bien, es generalizado en los países compuestos: la atribución a la Federación de un mismo haz de competencias sustanciales, como son relaciones 
internacionales ${ }^{19}$, defensa, aduanas y comercio exterior, sistema monetario, política económica, legislación laboral, civil y penal, que constituyen el núcleo duro de las competencias federales; la cláusula residual a favor de las entidades federadas; el principio de lealtad federal que obliga a respetar en el ejercicio de las competencias los intereses de otras colectividades; la atribución de una función colegisladora a la Cámara Alta, con independencia que se opte por asignar un número idéntico de senadores por Estado Miembro o un número variable en relación proporcional con su población; y la asignación al Tribunal Constitucional o a la Suprema Corte la composición de conflictos en materia territorial.

No obstante, no puede obviarse que aún siendo decisiva la cuestión del reparto de competencias entre los niveles de gobierno, el grado de descentralización política de un país depende no sólo del quantum de competencias que hayan sido atribuidas a las entidades territoriales que lo componen, sino también de que dispongan de un volumen de ingresos propios -esto es, no transferidos- suficientes para el desempeño de las funciones asumidas, sin perjuicio de que sean complementados por transferencias estatales, cuando no pueda satisfacerse las necesidades de financiación con sus recursos tributarios. Un adecuado sistema de financiación de los servicios a cargo de las entidades territoriales, en especial salud y educación, es determinante para la autonomía de los niveles de gobierno, es la otra cara de la moneda de todo proceso de distribución territorial del poder y, por tanto, el otro gran reto pendiente, junto con la reordenación de las competencias, que debe afrontar la reorganización territorial del poder público en Colombia.

Finalmente, resaltar que aún siendo la futura ley orgánica de ordenamiento territorial un instrumento normativo adecuado para la construcción de una nueva organización territorial plural y democrática, quizás la Constitución escrita sea la norma más idónea para regular, al menos, en sus líneas esenciales, estos elementos fundamentales en la organización política de los Estados Compuestos, sin perjuicio de una remisión a las leyes, en especial con un valor cualificado, para completar la ordenación constitucional, y de que a tal concreción contribuyan también los órganos supremos de justicia constitucional mediante su labor interpretativa.

\section{Referencias}

SÁNCHEZ, A. I. (1997), Federalismo e integración europea. La distribución de competencias en los sistemas alemán y comunitario, Bilbao, IVAP,

CABELLOS, M. A. (2006), "Los resultados del proceso de reforma del federalismo en Alemania", en Revista General de Derecho Constitucional [en línea:], núm. 2, disponible en: disponible en: http://www.iustel.com

República Federal de Alemania (1949), Ley Fundamental (Grundgesetz), Berlín.

República de Austria (1929), Constitución Federal, Viena.

\footnotetext{
${ }^{19}$ No obstante, en los cuatro países estudiados se les reconoce a los Estados Miembros, si bien con variados condicionamientos y limitaciones, el poder de establecer tratados internacionales (treaty making power).
} 
